\title{
The Production Measurement Model of Open Pit Mine Based on Truck Operation Diagram
}

\author{
Xiao-Yu SUN, Xiao KONG and Wei-Guo ZHANG \\ School of Resources \& Civil Engineering, Northeastern University, Shenyang 110819, China
}

\begin{abstract}
Conventional production measurement of truck dispatching system in open pit mine has not been effectively expressed by a mathematical model, whichbrings a negative effect on the subsequent data mining and a compatibility issue to apply the production measurement with fixed assignment of truck. In this study, based on the proposed concept that truck is not only the carrier of transport material, but also act as the bridges and linkages between the loadingsites and the unloading sites, a new truck operation diagram was established, which was further developed to a basic data matrix and a production measurement model. The new model allowed to calculatethe production measurement of the transport, loading, unloading, material and etc, respectively, as well as with any calculation in combination of more than one factor as needed.It solved the compatibility issue between conventional production measurement and the production measurement of fixed assignment of truck with good practical results.
\end{abstract}

\section{Introduction}

The production process of an open pit mine is mainly completed by both mining and transporting equipment. With the continuous development of equipment size, mechanization, and automation [1], it is more and more important for the equipment to be automated in production measurement, scientific assessment and highly efficient in management[2].

Traditionally, manual production organization of open pit mine uses fixed assignment of truck, that is, each truck fixed on one loading site and one unloading site. Only can we know the production output of each truck, the production output of each loading and unloading site can be calculated. At the same time, the distance between the two sites is a fixed value, therefore, it is very easy to calculate the distance and the ton-kilometre. The production measurement mainly counts output and distance, which is for calculating contracted unit and drivers' payment.

However, automatic dispatching system assigns truck in an optimized and random way, the fixed relationship between truck loading site and unloading site is no longer existed. Therefore, a logic conventional measurement processing is developed as follows[3]:

(1) First of all, equipment status can be recognized according to the mining - transportation - unloading process, and the key information is to determine both loading and unloading sites of a truck;

(2)Also, with the determined loading and unloading sites, production and transportation distance data can be generated and stored under the categories of trucks, loading sites, unloading sites and materials, and ultimately the generated data forms the database by taking "shift" as the unit;

(3) Finally, based on the shift database, daily production, monthly production statistics can be further completed.

However, the main problems of this approach is:

(1) It is not compatible to the traditional fixed assignment of truck.

(2) The process is complex, and has not been effectively expressed by a mathematical model.

(3) Calculation results were independently stored by trucks, loading sites, unloading sites and materials with no indication of the relationship of mining transportation - unloading, such information plays a significant role for the analysis of the production process and mining production potential ${ }^{[4-6]}$. For example, when problem occurs, the only way for back tracing of a measurement is to use the trajectory playback mode, such as indicated in Figure 1, which has poor visualization and time consuming.

\section{General idea}

The operation process of a single truck is a repeated process from first loading $\rightarrow$ first unloading $\rightarrow$ second loading $\rightarrow$ second unloading $\rightarrow \ldots \rightarrow$ n-th loading $\rightarrow$ n-th unloading. Although automatic dispatching system does not have the fixed loading and unloading sites as in the fixed assignment of truck, but for every delivery, the corresponding loading and unloading sites are still existing and unique. That is to say, for fixed assignment, every truck has the corresponding loading and unloading sites, and for automatic dispatching system, the 
production of each delivery have corresponding sites for loading and unloading. Therefore, in both cases, the logic that truck is the material carrier and the link to connect the two sites remains the same. Since fixed assignment can calculate the product of loading and unloading sites from the data of trucks' production, then the same rational should be also apply for the optimized and random assignment if the problem of measuring trucks can be solved. In addition, the solution can be used to deal with the mining, unloading, materials measurement problems.

So, this paper put forward the concept of truck operation diagram, which is shown in Figure 2, wherethe $\mathrm{X}$ axis represents time and the $\mathrm{Y}$ axis represents loading and unloading sites; and, the solid lines indicates that truck is heavy, and the dash lines indicates truck is empty. Also, different colours represent different materials as the condition may apply. Through the graph, it is very clear to see the number of deliveries have been made by a truck, and the type of material and the locations of load and unload of each time truck transportation.

From Figure 2, the corresponding data structure can be built, and the inter-conversion between the data structure and the diagram can be performed. And then, through the model, it can be easily used to calculate the production of loading sites, unloading sites, delivery trucks and conveyed materials. And, the model also provides the flexibility for combination calculations. However, it is noted that the model lacks the required information of distance to calculate mileage and ton-kilometre. Therefore, for the convenience of application, we use the approach of cumulating the loading and unloading site mileage.

\section{Measurement Model}

\subsection{Basic Data Matrix}

Suppose that the following 4 sets: loading site (shovel) set $\mathrm{S}$, unloading sites set $\mathrm{U}$, material set $\mathrm{M}$, trucks set $\mathrm{C}$.

For a single truck $\mathrm{c}$ in $\mathrm{C}$, the number of completed truck is $\mathrm{n}_{\mathrm{c}} . \quad \mathrm{n}_{\mathrm{c}} \times 8$ matrix is established as follows:

$$
\mathbf{A}_{\mathbf{c}}=\left[\begin{array}{l}
a_{1,1}^{c}, a_{1,2}^{c}, \ldots, a_{1,8}^{c} \\
a_{2,1}^{c}, a_{2,2}^{c}, \ldots, a_{2,8}^{c} \\
\ldots \\
a_{n_{c}, 1}^{c}, a_{n_{c}, 2}^{c}, \ldots, a_{n_{c}, 8}^{c}
\end{array}\right]
$$

1-3 column $a_{i, 1}^{c}, a_{i, 2}^{c}, a_{i, 3}^{c}$ : the i-th loading information of truck c, respectively is the loading site index, loading time and the truck accumulated running mileage. $a_{i, 1}^{c} \in S\left(i=1, \ldots, n_{c}\right)$.

4-6 column $a_{i, 4}^{c}, a_{i, 5}^{c}, a_{i, 6}^{c}$ : the i-th time unloading information of truck $c$, respectively is unloading site index, unloading time, trucks accumulated running mileage, $a_{i, 4}^{c} \in \mathrm{U}\left(i=1, \ldots, n_{c}\right)$.
7 column $a_{i, 7}^{c}$ : The i-th transport materials of truck c.

8 column $a_{i, 8}^{c}$ : The i-th transport weight or volume of truck c.

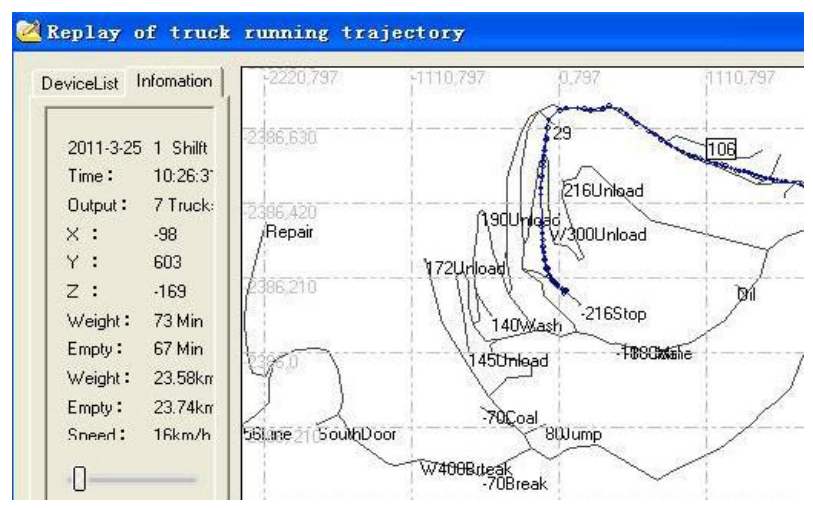

Figure1.Replay of truck running trajectory

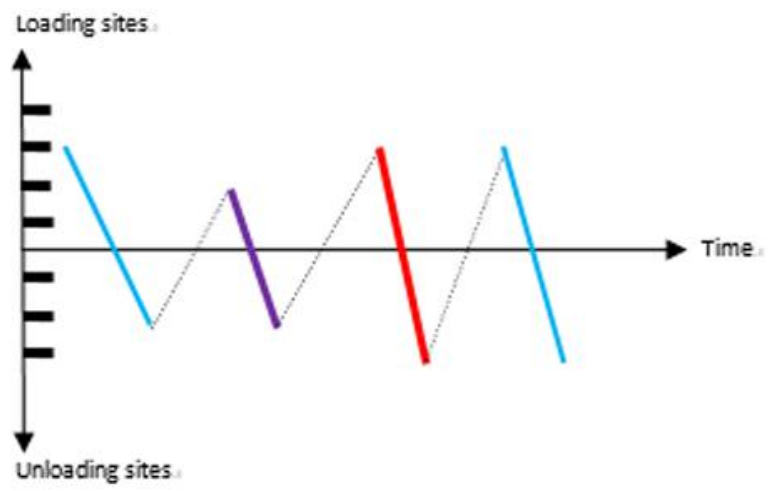

Figure2. Truck operation diagram

\subsection{Calculation column vector}

The matrix has recorded each truck's transport loading site, unloading site, transport material, loading time and unloading time, the cumulative running mileage of arriving at the loading site and unloading site. Based on it, through defining the following five different $n_{c}$ dimensional column vector $[7,8]$, so that a variety of production calculation can be obtained.

(1) $n_{c}$ dimensional column vector of truck c loading at shovel s:

$$
\overrightarrow{\mathbf{V}}_{\mathrm{c}, s}=\left[V_{\mathrm{i}}^{c, s}\right]_{n_{\mathrm{c}}}
$$

Its elements are as follows:

$$
V_{\mathrm{i}}^{c, s}=\left\{\begin{array}{l}
1, a_{i, 1}^{c}=s \\
0, \text { others }
\end{array}\right.
$$

(2) $n_{c}$ dimensional column vector of truck c unloading at unload site $\mathrm{u}$ :

$$
\overrightarrow{\mathbf{V}}_{\mathrm{c}, \mathrm{u}}=\left[V_{\mathrm{i}}^{c, \mathrm{u}}\right]_{n_{\mathrm{C}}}
$$

Its elements are as follows: 


$$
V_{\mathrm{i}}^{c, \mathrm{u}}=\left\{\begin{array}{l}
1, a_{i, 4}^{c}=u \\
0, \text { others }
\end{array}\right.
$$

(3) nc dimensional column vector of truck c transporting material $\mathrm{m}$ :

$$
\overrightarrow{\mathbf{V}}_{\mathrm{c}, \mathrm{m}}=\left[V_{\mathrm{i}}^{c, \mathrm{~m}}\right]_{n_{c}}
$$

Its elements are as follows:

$$
V_{\mathrm{i}}^{c, \mathrm{~m}}=\left\{\begin{array}{l}
1, a_{i, 7}^{c}=\mathrm{m} \\
0, \text { others }
\end{array}\right.
$$

This column vector is used to aggregate production and mileage.

(5) Ac matrix extract $\mathrm{j}$-th column to be $\mathrm{n}_{\mathrm{c}}$ dimensional column vector:

$$
\overrightarrow{\mathbf{A}}_{\mathbf{j}}^{c}=\left[\begin{array}{l}
a_{1, j}^{c} \\
a_{2, j}^{c} \\
\cdots \\
a_{n_{c}, j}^{c}
\end{array}\right], \mathbf{j}=1,2, \ldots, 8 .
$$

This column vector is used to extract 3-rd,6-th, 8 -th, which can be used to calculate mileage, production, ton-kilometre.

\subsection{Calculation Method}

This paper includes transportnumber of truck, production $\left(\mathrm{m}^{3}\right.$ or $\left.\mathrm{t}\right)$, and mileage $(\mathrm{km})$, to prevent such ambiguity, defined as follows:

Definition 1: truck running ton kilometre $=\sum$ truck single volume $\times$ heavy transport mileage.

Definition 2: average distance $=$ truck heavy transport mileage $\div$ heavy truck number, according to the truck, shovel, unloading site, the material alone or in combination calculation. Such as material $\mathrm{m}(\mathrm{mM})$ average distance is the average distance of all the transport material truck, similarly known the meaning of shovel and the unloading site.

\subsubsection{General Calculation}

The loading number of truck $\mathrm{c}$ in shovel s:

$$
n_{c}^{s}=\overrightarrow{1}^{\mathrm{T}} \overrightarrow{\mathrm{V}}_{\mathrm{c}, \mathrm{s}}
$$

$$
n_{c}^{u}=\overrightarrow{1}^{\mathrm{T}} \overrightarrow{\mathrm{V}}_{\mathrm{c}, \mathrm{u}}
$$

The number of truck $\mathrm{c}$ transporting materiel $\mathrm{m}$ :

$$
n_{c}^{m}=\overrightarrow{1}^{\mathrm{T}} \overrightarrow{\mathrm{V}}_{\mathrm{c}, \mathrm{m}}
$$

The loading quantity of truck $\mathrm{c}$ in shovel s:

$$
G_{c}^{S}=\left[\overrightarrow{\mathrm{A}}_{8}^{\mathrm{c}}\right]^{\mathrm{T}} \overrightarrow{\mathrm{V}}_{\mathrm{c}, \mathrm{s}}
$$

The unloading quantity of truck c in unloads site u:

$$
G_{c}^{u}=\left[\overrightarrow{\mathrm{A}}_{8}^{\mathrm{c}}\right]^{\mathrm{T}} \overrightarrow{\mathrm{V}}_{\mathrm{c}, \mathrm{u}}
$$

The quantity of truck c transporting materiel $\mathrm{m}$ :

$$
G_{c}^{m}=\left[\overrightarrow{\mathrm{A}}_{8}^{\mathrm{c}}\right]^{\mathrm{T}} \overrightarrow{\mathrm{V}}_{\mathrm{c}, \mathrm{m}}
$$

\subsubsection{Truck Calculation}

The transport number of truck $\mathrm{c}: \mathrm{n}_{\mathrm{c}}$

The transport quantity of truck c:

$$
G_{c}=\overrightarrow{1}^{\mathrm{T}} \overrightarrow{\mathrm{A}}_{8}^{c}
$$

The transport ton kilometre of truck c:

$$
W_{c}=\left[\overrightarrow{\mathrm{A}}_{8}^{\mathrm{c}}\right]^{\mathrm{T}}\left(\overrightarrow{\mathrm{A}}_{6}^{c}-\overrightarrow{\mathrm{A}}_{3}^{\mathrm{c}}\right)
$$

Truck heavy transport mileage:

$$
D_{c}^{f u 11}=\overrightarrow{1}^{\mathrm{T}}\left(\overrightarrow{\mathrm{A}}_{6}^{\mathrm{c}}-\overrightarrow{\mathrm{A}}_{3}^{\mathrm{c}}\right)
$$

The total transport mileage of truck:

$$
D_{c}^{\text {total }}=A_{n_{c}, 6}-A_{1,3}
$$

The empty transport mileage:

$$
D_{c}^{\text {empty }}=D_{c}^{\text {total }}-D_{c}^{\text {full }}
$$

The average transport distance of truck c:

$$
d_{c}=D_{c}^{\text {full }} / n_{c}
$$

The reason that the total mileage was calculated first and then the empty mileage is that not only the total mileage is easy to calculate, but also in order to unify the calculation with matrix. In addition, it was to ensure that the model has a strong versatility, practicality and can be extension for future use. Otherwise, the empty mileage calculation requires an additional model and algorithm.

The unloading number of truck $\mathrm{c}$ in unloads site $\mathrm{u}$ : 


\subsubsection{Shovel Calculation}

According to type (7), (10) and definition 2, three types can be getting as follows:

The loading number of shovel s:

$$
n_{s}=\sum_{c \in C} n_{c}^{s}=\sum_{c \in C} \overrightarrow{1}^{\mathrm{T}} \overrightarrow{\mathrm{V}}_{c, s}
$$

The loading quantity of shovel s:

$$
G_{S}=\sum_{c \in C} G_{c}^{s}=\sum_{\mathrm{c} \in C}\left[\overrightarrow{\mathrm{A}}_{8}^{\mathrm{c}}\right]^{\mathrm{T}} \overrightarrow{\mathrm{V}}_{\mathrm{c}, \mathbf{s}}
$$

The average transport distance of shovel s:

$$
d_{s}=\frac{1}{n_{s}} \sum_{\mathrm{c} \in C}\left(\overrightarrow{\mathbf{A}}_{6}^{c}-\overrightarrow{\mathrm{A}}_{3}^{\mathrm{c}}\right)^{\mathrm{T}} \overrightarrow{\mathrm{V}}_{\mathrm{c}, \mathrm{s}}
$$

\subsubsection{Unloading Site Calculation}

According to type (8), (11) and definition 2, three types can be get as follows:

The unloading number of unloading site $\mathrm{u}$ :

$$
n_{u}=\sum_{c \in C} n_{c}^{u}=\sum_{\mathrm{c} \in C} \overrightarrow{1}^{\mathrm{T}} \overrightarrow{\mathrm{V}}_{\mathrm{c}, \mathrm{u}}
$$

The unloading quantity of unloading site $\mathrm{u}$ :

$$
G_{u}=\sum_{\mathrm{c} \in C} G_{c}^{u}=\sum_{\mathrm{c} \in C}\left[\overrightarrow{\mathrm{A}}_{8}^{\mathrm{c}}\right]^{\mathrm{T}} \overrightarrow{\mathrm{V}}_{\mathrm{c}, \mathrm{u}}
$$

The average transport distance of unloading site $\mathrm{u}$ :

$$
d_{u}=\frac{1}{n_{u}} \sum_{\mathrm{c} \in C}\left(\overrightarrow{\mathrm{A}}_{6}^{\mathrm{c}}-\vec{A}_{3}^{\mathrm{c}}\right)^{\mathrm{T}} \overrightarrow{\mathrm{V}}_{\mathrm{c}, \mathrm{u}}
$$

\subsubsection{Material Calculation}

According to type (9), (12) and definition 2, three types can be getting as follows:

The number of material $\mathrm{m}$ :

$$
n_{\mathrm{m}}=\sum_{\mathrm{c} \in C} n_{c}^{m}=\sum_{\mathrm{c} \in C} \overrightarrow{1}^{\mathrm{T}} \overrightarrow{\mathrm{V}}_{\mathrm{c}, \mathrm{m}}
$$

The quantity of material $\mathrm{m}$ :

$$
G_{m}=\sum_{\mathrm{c} \in C} G_{c}^{m}=\sum_{\mathrm{c} \in C}\left[\overrightarrow{\mathrm{A}}_{8}^{\mathrm{c}}\right]^{\mathrm{T}} \overrightarrow{\mathrm{V}}_{\mathrm{c}, \mathrm{m}}
$$

The average transport distance of material $\mathrm{m}$ :

$$
d_{m}=\frac{1}{n_{m}} \sum_{c \in C}\left(\overrightarrow{\mathrm{A}}_{6}^{\mathrm{c}}-\overrightarrow{\mathrm{A}}_{3}^{\mathrm{c}}\right)^{\mathrm{T}} \overrightarrow{\mathrm{V}}_{\mathrm{c}, \mathrm{m}}
$$

\subsubsection{Combination Calculation}

Based on $\overrightarrow{\mathbf{V}}_{\mathrm{c}, \mathrm{s}}, \overrightarrow{\mathbf{V}}_{\mathrm{c}, \mathrm{u}}, \overrightarrow{\mathbf{V}}_{\mathrm{c}, m}$, we can derive other column vectors forconducting combination calculations in a flexible way, such as the average distance between loading and unloading sites, summary of different loading materials of loading sites and unloading sites, the details of material transportation between the loading and the unloading site and so on. For example, the calculation of loading and unloading transport distance as follow:

According to $\overrightarrow{\mathbf{V}}_{\mathrm{c}, \mathrm{s}}, \overrightarrow{\mathbf{V}}_{\mathrm{c}, \mathrm{u}}, \mathrm{n}_{\mathrm{c}}$ dimensional vectors are defined as follows:

$$
\overrightarrow{\mathbf{V}}_{\mathrm{c}, \mathrm{s}, \mathrm{u}}=\left[V_{\mathrm{i}}^{c, s, \mathrm{u}}\right]_{n_{c}}
$$

Its elements are as follows:

$$
V_{\mathrm{i}}^{c, s, \mathrm{u}}=V_{\mathrm{i}}^{c, s} \times V_{\mathrm{i}}^{c, \mathrm{u}}
$$

The average transport distance of loading $s$ and unloading $\mathrm{u}$

$$
\mathrm{d}_{s, u}=\frac{\sum_{c \in C}\left(\overrightarrow{\mathbf{A}}_{6}^{c}-\overrightarrow{\mathbf{A}}_{3}^{\mathbf{c}}\right)^{\mathrm{T}} \overrightarrow{\mathrm{V}}_{\mathrm{c}, \mathbf{s}, \mathbf{u}}}{\sum_{c \in C} \overrightarrow{\mathbf{1}}^{\mathrm{T}} \overrightarrow{\mathrm{V}}_{\mathrm{c}, \mathrm{s}, \mathrm{u}}}
$$

\section{Application and discussion}

According to this model, the corresponding measurement procedure is programmed through VB embedded MatrixVB way [9, 10]. Some measurement results of the actual application in an open pit mine are shown in Figure 3 to figure 6.

Discussion as follows:

(1) The fixed assignment of truck is a special case of this method.For any truck $\mathrm{c}$ in $\mathrm{C}$, the loading and unloading sites are fixed, so all $a_{i, 1}^{c}\left(\mathrm{i}=1,2, \ldots, \mathrm{n}_{\mathrm{c}}\right)$ in (1) are same, as well as $a_{i, 4}^{c}\left(i=1,2, \ldots, \mathrm{n}_{\mathrm{c}}\right)$. Therefore, this method is fully compatible with the measurement method of fixed assignment of truck.

(2) Equations insection 2.3.2, 2.3.3, 2.3.4, 2.3.5 are derived for the calculations based on trucks, loading site, unloading site and material, which is the main component in conventional measurement method. Therefore, this method can easily export conventional econometric results. However, the conventional method cannot perform any combination calculation as indicated in section 2.3.6. Therefore, this method is fully compatible with conventional measurement methods of random assignment of truck.

(3) Usually, a load distance is represented by the distance between the loading and unloading site. In order to correspond to the base matrix data structure, the total running mileage of loading site and unloading site were used to represent load distance, that is $a_{i, 3}^{c}, a_{i, 6}^{c}$ in (1), in this paper. This approach has the following advantages: 
- it can easily derive load distance between loading and unloading site;

- subtraction can be used for calculation distance of any period of time, without piecewise summation;

- it can be checked with the odometer by the driver;

- it can be used to trace the mileage for equipment maintenance purpose.

(4) Conventional methods storage measurement results of trucks, shovels, unload site, material independently, which does not reflect the relationships between each other. The matrix can be more effectively reflect the relationships between loading, transportation and unloading, and it is easy to derive independent measurement results.

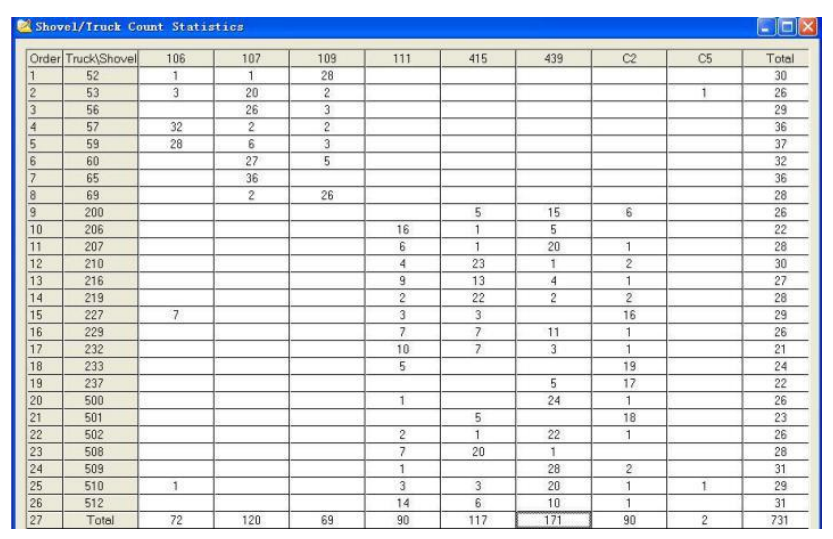

Figure 3.Comparison of Shovel-Truck loading results

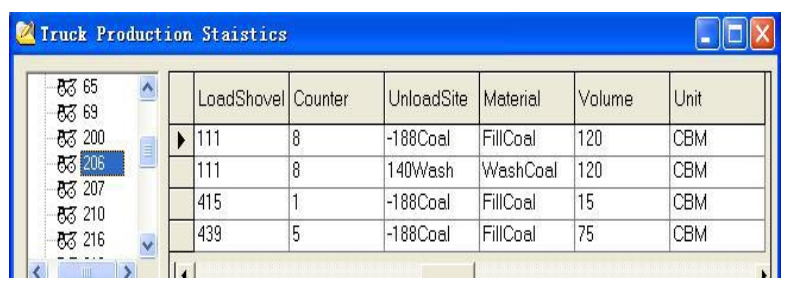

Figure4.Summary of No. 206 truck production output

\begin{tabular}{|c|c|c|c|c|c|c|c|}
\hline \multicolumn{7}{|c|}{ Q Shovel Production Staistics } & - $\square x$ \\
\hline \multirow{8}{*}{ 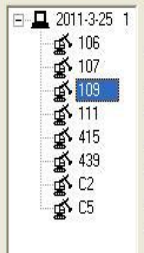 } & & LoadTruck & Counter & UnloadSite & Material & Volume & Unit \\
\hline & D & 52 & 28 & -170 Sand & Sand & 1092 & CBM \\
\hline & & 53 & 2 & -170Sand & Sand & 90 & CBM \\
\hline & & 56 & 3 & -170Sand & Sand & 117 & CBM \\
\hline & & 57 & 2 & -170 Sand & Sand & 90 & CBM \\
\hline & & 59 & 3 & -170 Sand & Sand & 117 & CBM \\
\hline & & 60 & 5 & -170 Sand & Sand & 225 & CBM \\
\hline & & 69 & 26 & -170 Sand & Sand & 1014 & CBM \\
\hline
\end{tabular}

Figure5.Summary of No. 109 shovel production output

A Iaterial Production Staistics
\begin{tabular}{|l|l|l|l|l|}
\hline & Material & Counter & Volume & Unit \\
\hline & FillCoal & 293 & 3966 & CBM \\
\hline & LeanOre & 83 & 1176 & CBM \\
\hline & PickCoal & 51 & 720 & CBM \\
\hline & RichOre & 121 & 5019 & CBM \\
\hline & Sand & 141 & 5568 & CBM \\
\hline & Soil & 1 & 12 & CBM \\
\hline & WashCoal & 41 & 582 & CBM \\
\hline 4 & & & \\
\hline
\end{tabular}

Figure6.Summary of material production

\section{Conclusion}

This paper developed a mathematical model and data structure based on the proposed the truck operation diagram in open pit mine. The model was proven compatible with production measurement methods for both fixed assignment and conventional random assignment of truck. The data structure was used to calculate production measurement of loading, transportation, unloading and materials, respectively and in combinations with more than one factor. The model also showed better versatility, practicality and potential for expansion, which is significant for analysing production process and mining production potential.

\section{References}

1. M. B. Khorzoughi, R. Hall, Int. J. Min. Reclam. Env, 29, 380(2015)

2. D. K.Ahangaran, A B Yasrebi, A Wetherelt, P. Foste,Arch. Min. Sci, 57, 39(2012)

3. X. M. Zheng, Y. F. Qiao, Metal Mine, 11,103(2008).

4. Q. H. Gu, C. W. Lu, S. G. Jing,Journal of Mines, Metals and F, 63, 126(2015)

5. S. Alarie, M. Gamache,Int J Surf Min Reclamat Enviro, 16,59(2002)

6. X. Y. Sun, Y. T. Yu, X. T. Wang, Z. Y. Yang, C. Y. Chen,Mining Engineering, 3,41(2005)

7. G.Strang,Linear algebra and its applications(Thomson Learning Inc, 2007)

8. L. F. Liu,Linear algebra(Northeastern University press, Shenyang, 2014)

9. Microsoft Corporation,Microsoft visual basic .Net language reference (Microsoft Press,2008)

10. Bradley, J. Case, Programming in visual basic, version 6.0(McGraw-Hill/Irwin, Boston, 2002) 